\title{
Exploring the Triggers of Transformational Change in the South African Department of Correctional Services
}

\author{
Mbongeni A. Mdletye \\ Jos Coetzee \\ Wilfred I. Ukpere \\ Department of Industrial Psychology and People Management, Faculty of Management \\ University of Johannesburg, Johannesburg, South Africa \\ E-mail: wiukpere@uj.ac.za, mbongeni@telkomsa.net
}

Doi:10.5901/mjss.2014.v5n10p596

ABSTRACT

Change is a critical phenomenon in any organisation that wants to optimise its performance at individual, team and organizational levels in order to survive and remain competitive in the intensely competitive and globalised operational environment - be it economic, social, political, technological, international or labour market environment. This paper presents empirical evidence gathered from research participants in the Correctional Centres located in the KwaZulu-Natal Region of the Department of Correctional Services on the factors that triggered the fundamental culture change from the punishment-oriented philosophy to the rehabilitation-driven philosophy in terms of the treatment of sentenced offenders (herein referred to as DCS change). An interest in the triggers of transformational change within a correctional environment has motivated the authors to embark on an empirical study which sought to establish the triggers of the transformational change in the Department of Correctional Services of South Africa. The study was significant, particularly if one considers the fact that there is generally an interest in the factors that force organisations to initiate and implement organisation-wide changes. Change and transformation strategists, organisation development practitioners, and managers in general in both the public and private sector globally and in South Africa in particular will benefit from the study, particular if one considers the fact that transformational change interventions are currently being implemented across the South African public service as part of the government's agenda of reconstructing and developing the South African society. An extensive literature study on the external and internal triggers of organisational change was undertaken as part of contextualising the triggers of transformational change within the South African Correctional Services environment in general. The literature study was followed by the empirical study which focused on gathering data from correctional officials and offenders through utilising two survey questionnaires. The empirical findings revealed that the fundamental culture change from the punishment-oriented philosophy which was characterised by nonexistence of a human rights culture to a rehabilitation-focused philosophy underpinned by the promotion and maintenance of a human rights culture was sparked off by various internal and external factors. These ranged from financial, social and political reasons to complaints about service from offenders, complaints from national and international bodies regarding human rights violations, competitive forces, proactive and progressive leadership, and the need to reduce recidivism.

Keywords: Change, organisational change, transformation, organisational transformation, transformational change, causes of organisational change

\section{Introduction and Background}

In the continuously changing globalised operational environment, organisations are called upon to enhance their performance in terms of effectiveness and efficiency through effecting improving on their structures, systems, processes, and practices. And organisations can only enhance their performance at individual, team and organisational levels through undertaking transformational changes in terms of their human and non-human elements. It is for this reason that Wharton Executive Education (2011) regards change as key to organisational growth and survival. Regarding change as critical to organisational growth, development and survival means that organisations that want to promote their competitive advantage must engage in change, for if an organisations do not change, they become stagnant and irrelevant and eventually go under (Bourne \& Bourne, 2002; Palmer, Dunford \& Akin, 2009; Johnson, 2012). Bridle (2010, p.56) emphasises that "if you are going to continue doing the same thing, you are going to get the same result." This explains why organisations that do not embrace and implement change end up going out of business. They are driven out of business due to their failure to maintain a competitive edge through implementing relevant changes that are in line with 
the changing conditions within the external environment. The changing circumstances in the external environment of the organisation include the changing and increasing needs of clients, the globalisation of the operational environment, increasing competition as a result of globalisation, the need to bolster and increase organisational efficiency through controling costs, as well as technological advancement (Corbeau \& Sijats, 2005; Palmer, Dunford \& Akin, 2009; Kohurt, 2010; Turner, 2011). The above-mentioned factors become an impetus for change. They are the reason behind organisational changes taking place at an ever-increasing rate within the modern business environment (Burnes, 2004; Imberman, 2009; Kohurt, 2010; Agboola \& Salawu, 2011; Turner, 2011). Therefore, in the light of the above, change becomes a critical and inevitable phenomenon of organisational life (Lew \& Eekhout, 2004; Flash, 2007; Maltz, 2008; Lefkoe, 2010), which is inextricably linked to both human and organisational life.

\subsection{Problem statement}

Change is one phenomenon which remains inevitable in the life of any organisation. Any organisation that does not change as dictated to by its internal and external environments face extinction. Given the dynamic and ever-changing business environment, organisations must change in order to adjust and adapt to their changing organisational environments. Organisations that have learnt to anticipate, direct and cope with changes within their organisational environments because they are led by proactive and progressive leaders, are able to ensure and maintain their stability, survival, sustainability, and competitive edge within the fiercely competitive and globalised business environment. On the other hand, the failure to anticipate, direct and cope with changes, coupled with the absence or lack of proactive and progressive leadership, contributes to the demise of organisations in terms of their stability, competitiveness, survivability and sustainability.

\subsection{Objectives}

The following are the objectives of the paper:

- To emphasise the need for organisations to anticipate changes within their organisational environments internal and external environments.

- To accentuate the importance of organisations that have proactive and progressive leadership that enables organisations to anticipate, direct and cope with changes within their internal and external environments.

- To establish and explore various triggers of transformational change within the South African Department of Correctional Services, so that managers in general across the business spectrum can learn from these with a view to improving on their management of the current and future transformational change initiatives; and

- To stress the importance of managers in managing, through decisive managerial action, changes that emanate from both the internal and external organisational environments, which may impact either positively or negatively on organisational effectiveness and efficiency.

\subsection{Significance and contributions of the study}

The findings of the study will enhance the existing literature on the triggers of transformational change in that they will add more empirical evidence, particularly when it comes to the importance of anticipating, directing, and coping with change that stems from the internal and external organisational environment. The outcome of the study will be of significant value to change strategists, change implementers, change recipients, organistional development practitioners and managers in general, who are charged with the enormous responsibility of initiating, implementing, institutionalising and sustaining transformational change efforts which are part of organisations' ongoing efforts to improve organisational performance in order to remain competitive within a globalised operational environment. The study's setting within the Department of Correctional Services will enhance and deepen the understanding of Correctional Services' managers at change strategist level, change implementation level, and change recipient level insofar as transformational change management in terms of change anticipation, direction, and coping is concerned, particularly when it comes to the facilitation of effective and efficient transformational change management at personal, team and organisational levels.

\section{Literature Review on the Triggers of Transformational Change}

For any organisation to prosper and gain sustainability and competitive edge in terms of its business performance, there 
should be a commitment to implementing organisational changes on a continuous basis as a reaction to changes in the internal and external environments of the organisation. Commitment to initiating and implementing changes assists in ensuring that organisations improve on their business performance. Otherwise if organisations do not improve on their performance through implementing changes continuously, they will continue to produce mediocre performance on an ongoing basis. It is for this reason that Bridle (2010) emphasises that if and when organisations perform at the same level all the time, they will produce one and the same results all the time. Therefore, it becomes imperative for organisations to demonstrate a strong sense of commitment to initiating, implementing and institutionalising changes ceaselessly if they are to fulfill and maintain their urge for competitive advantage.

What are the factors that compel organisations to change? It was earlier indicated in the foregoing paragraphs that there are certain factors residing in both the internal organizational and external organisational environments that compel organisations to undergo changes. These vary from the need to contain operational costs and the need to enhance organisational effectiveness and efficiency (internal organisational environmental factors) to the high and advanced rate of technological change, the globalisation of economy and work, increasing competition due to globalization, as well as the changing and increasing needs and interests of customers (external organisational environmental factors)(Cook, Macaulay and Coldicott,2005, Palmer, Dunford and Akin, 2009, Kohurt, 2010, and Turner, 2011). This suggests that the internal and external environmental factors play a critical role in triggering change in organisations and that change, brought about by these internal and external environmental factors, plays a significant role in facilitating the enhancement of business performance. This further means that organisations are compelled to undergo changes on an ongoing basis as a response to the changing circumstances in terms of the political, economic, social, and technological arenas within the external environment (Osborne \& Brown, 2005). Therefore, adjusting and adapting to the changing environmental conditions is a necessity if organisations are to remain relevant and competitive. For this reason, changes will forever happen in organisations, as they are the key to organisational relevance and competitiveness, and ultimately to organisational survival. Without change, organisations become stagnant, uncompetitive and boring (Johnson, 2012). The foregoing assertion makes change an integral, essential and unavoidable part of organisational life (Canadian Society for Chemical Engineering, 2004). Van de Ven and Poole (1995) suggest that the causes of organisational change can be explained in terms of some theoretical perspectives, namely teleological theory; life-cycle theory; and dialectical theory.

The teleological theory moves from the premise that organisational change denotes an organisation's efforts to achieve a desired state in terms of organisational performance through a continuous process of mission and vision revision, goal-setting and revision, execution, monitoring and evaluation, as well as restructuring (Van de Ven \& Poole, 1995). The life-cycle theory, on the other hand, postulates that organisations, as entities that depend on the external environment for survival, cycle through the stages of inception, development, maturation, and downswing and as such, change is required to keep an organisation within a state of development and sustainability rather than the stage of deterioration, collapse and disintegration. The dialectical theoretical perspective claims that organisations are like multicultural entities with opposing values. When one particular force dominates over others, new organisational values and goals are established, resulting in organisational change. From the above-named theoretical perspectives, one can construe that organisations do need organisational change in order to ensure their continued survival and sustainability. It is for this same reason that Lunenburg (2010) emphasises that organisational change denotes moving an organisation from its present state to the desired future state in order to increase its effectiveness. The above perspectives give answers to Jones (2004)'s question: Why do organisations need change? Jones (2004) concurs with Van de Ven and Poole (1995)'s theoretical perspectives when emphasising that from a passive perspective, organisational change occurs as a reaction to an ever-changing organisational environment, be it internal or external, or as a response to a current crisis situation. Furthermore, Jones (2004) states that organisational change is also triggered by a progressive manager.

From the assertion that organisational change is an organisation's response to the ever-changing conditions within the internal and external organisational environment, it can be concluded that the forces that drive organisational change are divided into two kinds, namely internal driving forces and external driving forces. Internal driving forces are those factors that obtain within the organisation and are generally under the control of the organisation; while external driving forces relate to situations that occur within the external environment of the organisation, i.e. outside of the organisation and are generally beyond the control of the organisation. Internal driving forces includes factors such as technological capacity, organisational culture, organisational systems and structures, and financial management; while external driving forces encompass factors such as customer behaviour in terms of needs, wants and desires, demographics in terms of changing population figures and density, economy, government laws and regulations, technological changes, political changes, as well as changes in the social environment. Due to the constantly changing situations within the internal and external environments of the organisation, the organisation need at all times to adapt to these changing conditions in order to remain relevant and effective (Blankstein, 2010; Lunenburg, 2010; Smylie, 2010; Creemers, 2011). As Duke 
(2011) puts it, organisations are not static and as such, they need to change on a continuous basis as a response to a variety of forces emanating from both the internal and external environments. For every change that takes place within an organisation, there is a driving force, cause or source behind such a change which can be traced back to either the internal or external environment (Fullan, 2011; Hargreaves, 2011; Spector, 2011). This suggests that all factors that are located within the internal and external environments of the organisation, be it institutions, individuals, groups, processes, demographic changes, or events, have an impact on how an organisation is being run.

The internal and external forces, causes, sources or drivers of organisational change are briefly discussed below.

\subsection{Internal drivers of organisational change}

The internal sources of organisational change are located within the internal environment of the organisation and are characterised by factors such as management policies, management styles, organisational structure, systems, procedures, practices and processes, performance gaps, workforce profile, changes at managerial level brought about by retirements, redeployments, resignations, and natural attrition, as well as mergers and acquisitions. It is the shortcomings in the abovementioned organisational variables that necessitate and bring about changes within the organisation (American Productivity and Quality Center (APQC) \& ICF Kaiser, 1997). The internal drivers are discussed below.

\subsection{Management policies}

Management policies also serve as a source of organisational change. Outdated policies that are used to manage organisational operations do not assist in promoting organisational performance in terms of effectiveness and efficiency and as such, a need arises to review them. This necessity to review outdated management policies implies change in the manner in which the organisation is managed (Senior, 2002).

\subsection{Management styles}

Inappropriate leadership behaviours and styles, such as inadequate direction, professional guidance, assistance, advice or support, may result in human resource and organisational identity challenges such as low employee morale, job dissatisfaction, negative organisational identification, low organisational commitment, low organisational loyalty, and negative organizational identity which all require change to be undertaken. Therefore, changes in leadership styles and the broader organisational culture variables as mentioned above have a considerable impact on the organisations in terms of how they are managed. This suggests that inappropriate leadership behaviours underpinning leadership styles do promote the need for change within an organisation (Senior, 2002).

\subsection{Organisational structure, systems, procedures, practices and processes}

Organisational structures, systems, procedures, practices and processes, which are utilised as vehicles for the enhancement of organisational performance in terms of effectiveness and efficiency, do serve as driving forces of organisational change. This is based on the fact that when these organisational performance-enhancing aspects become ineffective, the entire organisational operations management arrangement becomes deficient as well and this creates a need for change within the organisation (Lunenburg, 2010).

\subsection{Performance gaps}

Organisational inefficiencies create gaps in the performance of an organisation and these inefficiencies impact negatively on the delivery of services to the clients. This suggests that organisational inefficiencies coupled with poor service delivery lead to a situation whereby organisational goals and objectives are not being realised. Therefore, undertaking changes becomes necessary in order to close organisational performance gaps (Alexander \& Alexander, 2009).

\subsection{Workforce profile}

Human resources are an important asset in any organisation as organisational goals are achieved through and with people. People are the ones who carry out all activities within an organisation. This implies that organisational structures, systems, procedures and processes are meaningless without people. This further suggests that organisations can have 
the best structures, systems, procedures and processes, but without people in the chain of operations management, organisations won't be able to perform in terms of realising their goals and objectives. People in the organisation can be both managerial and non-managerial employees, and they all represent a source of organisational change. This is so because changes in the profile of the workforce (which bring about different work values and different employee behaviours and attitudes), high level of employee absenteeism, as well as excessive interpersonal conflict negatively affect the internal environment of the organisation and as such, change becomes necessary in order to address these (Bulach, Lunenburg, \& Potter, 2008; Lunenburg \& Ornstein, 2008).

\subsection{Personnel changes at managerial level}

Every new manager that joins an organisation brings his own ideas and ways of doing things into the organisation. Organisational relationships change due to changes in managerial personnel. Therefore, personnel changes at managerial level become a source of organisational change (Gibson, Ivancevich, Donnelly, \& Konopaske, 2012).

\subsection{Mergers and acquisitions}

Mergers and acquisitions create change in that they lead to negative consequences for employees such as employee redundancy which ultimately leads to job losses through retrenchments. This means that the need for organisational restructuring, which in certain cases leads to mergers and acquisitions, makes mergers and acquisitions a source of organisational change (Pearlstein, 1993).

\subsection{External drivers of organisational change}

The external causes of organisational change are located within the external environment of the organisation and are characterised by political, economic, social, and technological factors, acronymed PEST, PETS or STEP factors by Lunenburg (2010). These external forces include factors such as markets, clients, customers, suppliers, governments, labour unions, competitors, financial institutions, labour supply, levels of unemployment, economic climate, information and communication technology systems, globalisation of trade, political ideologies, and demographic changes. According to Lunenburg (2010), no organisation is an island. All organisations exist within a particular context and as such, they are influenced and affected by conditions obtaining within their external environment. The broader external environment, be it political, economic, social, or technological environment, is dynamic. It changes all the time and will continue to change. These changes in the political, economic, social and technological environment compel organisations to change in order to adapt to the changing and changed external environmental conditions. This is necessary for organisational survival and organisational sustainability. Lunenburg (2010) states that changes in the external environment of the organisation lead to significant changes within an organisation and as such, one can construe that the external organisational environment is the most powerful driver of organisational change (ChildHope, 2004). The external factors are explicated below.

\subsection{Political factors}

The political environment is dynamic and as such, it keeps on changing constantly due to various influences such as changes in governing parties as a result of changes in the preferences of the electorate. This leads to the disintegration of old alliances and the formation of new ones, leading to the establishment of new governments at national, provincial and local levels. This culminates into the promulgation of new laws, by-laws and regulations. It is for this reason that Lunenburg (2010) states that political factors, as an external source of organisational change, refer to laws, bylaws and regulations promulgated by parliaments and municipalities as institutions of government. Any changes in laws, bylaws and regulations affect the operations of organisations in the sense that these changes come with statutory obligations to comply with the laws and regulations. And as such, these legal pressures force organisations to change in order to comply with laws. Therefore, changes in laws and regulations as sources of change need to be respected by organisations and organisations need to demonstrate this respect through incorporating these new or revised laws and regulations in their own operations, systems, processes, procedures and structures (Bryson, 1988; Senior, 2002; ChildHope, 2004; Lunenburg, 2010). 


\subsection{Economic factors}

Economic factors relate to changes in general economic activity, such as changes in interest rates, inflation rates, exchange rates, supply and demand of products and services, credit policy, level of domestic and international trade, as well as competitors, suppliers, income, unemployment levels, and gross domestic product (GDP). All these economic factors do drive the need for organisations to change in terms of their operations, systems, procedures, practices, and processes (Senior, 2002; ChildHope, 2004; Brimley \& Garfield, 2009; Lunenburg, 2010).

\subsection{Social and cultural factors}

Every society has different social and cultural characteristics based on the location, racial and ethnic composition, human settlement, religious affiliation, gender, and cultural disposition. All these different factors do affect organisational operations. Social and cultural factors, as a source of organisational change denote people's values, habits, norms, attitudes and demographic characteristics. Changes in social and cultural factors become reflected in terms of people's aspirations, needs, wants, interests, and ways of working and living. These social changes are brought about by several forces such as people's level of education, urbanisation, feeling of autonomy, and international impact due to new information sources. These social changes affect the behavior of people in organisations. These changes compel organisations to adjust their operations in order to match the new trends in terms of demography, customers' buying patterns, and changing customer requirements (Senior, 2002; ChildHope, 2004; Brimley \& Garfield, 2009; Lunenburg, 2010).

\subsection{Technological factors}

Technological advancement does drive organisational change. When there is a change in technology in the external organisational environment and other organisations adopt the new technological resource, the competitiveness of the organisation that has not yet adopted the new technology is reduced due to organisational operations that become less cost-effective. This forces the organisation to adopt the new technology and the adoption means that the work structure of the organisation in terms of operations, procedures, systems, and processes become affected. This leads to the establishment of a new work structure and this signifies change taking place within an organisation as a result of adoption and utilisation of new technology. Therefore, new developments in technology do serve as drivers of organisational change (ChildHope, 2004; Brimley \& Garfield, 2009; Lunenburg, 2010; D’Agustino, 2011).

\subsection{Importance of effective leadership}

Given the above, for organisations to meet the challenges brought about by political, economic, socio-cultural, and technological changes, managers need to anticipate change and plan accordingly for effective improvements to organisational systems, procedures, practices, and processes. This requires organisational leadership that has tools or structures necessary to keep any change under control. This is what effective leadership in terms of change leadership is all about. Organisational leaders need to recognise and respond to all factors that affect their organisations. This lesson describes how the internal and external environments of an organisation drive change within the organisation. Therefore, for organisational leaders, the challenge is to anticipate and direct change processes so that organisational performance in terms of effectiveness and efficiency is improved (Szarlan, 2011).

\section{Methodology}

The research approach which was used in this study incorporated a literature study and a quantitative empirical study. On the methodology side, three types of research designs, namely the exploratory design, the survey design, and descriptive design were utilised and these point to a mixed method approach that was applied in the study. The three research designs each played a separate but interrelated role in conducting of this empirical study. For purposes of gaining a background insight into the research problem, the researcher did an extensive review of literatures. This was necessary in order to illuminate the research problem. For conducting a quantitative study of the sampled population, the researcher employed the survey research design (Kline, 2004). 


\subsection{Sample, sampling method and population}

A random, purposive and probability samples of 1000 correctional officials and 500 offenders were utilised in the study. A $13.17 \%$ sample for correctional officials and an $8.14 \%$ sample for sentenced offenders were drawn for the study. The sample was selected from a population of approximately 7593 correctional officials working in the seven management areas constituting the Department of Correctional Services in the KwaZulu-Natal Province and 13, 520 sentenced offenders.

\subsection{Research procedure}

The procedure followed in the execution of this empirical study entailed seeking permission to conduct research in the correctional centres from the Department of Correctional Services' Research Ethics Committee; conducting the pilot study; distributing and administering the survey questionnaires; and scoring and computing the responses. Two survey questionnaires, one for correctional officials and the other for offenders, were utilised to collect empirical data. A 4-point Likert type response scale was utilised in each of the questionnaires to measure views regarding the triggers of transformational change in the South African Department of Correctional Services. Tables 1 gives an example of the response scale utilised in respect of both correctional officials and offenders' questionnaires.

Table 1: Example of four-point response scale for correctional officials and offenders

\begin{tabular}{|l|l|l|l|l|}
\hline $\begin{array}{l}\text { The TRANSFORMATION described in section } 4.1 \text { was set in motion } \\
\text { (triggered) by ... } \\
\text { (Please place an X in the appropriate category) }\end{array}$ & $\begin{array}{c}\text { NOT at } \\
\text { all }\end{array}$ & $\begin{array}{c}\text { To SOME } \\
\text { extent }\end{array}$ & $\begin{array}{l}\text { To a LARGE } \\
\text { extent }\end{array}$ & $\begin{array}{c}\text { Almost } \\
\text { EXCLUSIVELY }\end{array}$ \\
\hline $\begin{array}{l}\text { Financial reasons (e.g. expenses or losses, reduced budgets) } \\
\text { Political reasons (e.g. as a result of the new political dispensation / } \\
\text { landscape in South Africa) }\end{array}$ & & & & \\
\hline $\begin{array}{l}\text { Appointment of new top managers (e.g. National Commissioner and Chief } \\
\text { Deputy Commissioners). }\end{array}$ & & & & \\
\hline
\end{tabular}

\subsection{Statistical analysis}

The statistical analysis focused on descriptive statistics with a view to providing proof that the two questionnaires used as measuring instruments were reliable and valid for the purpose of this study. In terms of sample statistics, frequency analysis was utilised to describe the sample obtained, as suggested by Kerlinger (1992). The responses on both questionnaires were subjected to factor analysis according to the procedure suggested by Nelissen and Scheepers (1992) in order to determine the factor structure of the two measuring instruments. To determine the adequacy and sphericity of the intercorrelation matrix, the Kaiser-Meyer-Olkin (KMO), measure of sampling adequacy (MSA) and the Bartlett's test of sphericity were conducted. A reliability analysis was also conducted on the measuring instruments with the purpose of calculating a reliability coefficient (Cronbach Alpha).

\subsection{Response rate}

Table 2 presents the composition of the sample and response rate in terms of both correctional officials and offenders. The return rate of $71.3 \%$ and the frequency rate of $98.2 \%$ for valid responses were recorded for correctional officials. For the offenders' sample, the return rate of $58.2 \%$ and the frequency rate of 97.6 for valid responses were recorded.

Table 2: Frequency Table of Participating Management Areas/Regional Office of the Obtained Sample

\begin{tabular}{lcccccc} 
Management Areas & \multicolumn{3}{c}{ Correctional Officials } & \multicolumn{3}{c}{ Offenders } \\
Durban & Frequency & \%age & Cum. \%age & Frequency & \%age & Cum. \%age \\
Glencoe & 113 & 15.3 & 15.3 & 79 & 27.1 & 27.1 \\
Ncome & 51 & 7.1 & 22.4 & 21 & 7.0 & 34.1 \\
Waterval & 86 & 12.0 & 34.4 & 71 & 25.9 & 60.0 \\
Kokstad & 144 & 19.7 & 54.1 & 90 & 29.3 & 89.3 \\
Empangeni & 101 & 13.8 & 67.9 & 30 & 10.0 & 99.3 \\
Pietermaritzburg & 17 & 2.4 & 70.3 & - & - & - \\
& 196 & 27.2 & 97.5 & - & - & - \\
& \multicolumn{7}{c}{0} \\
& \multicolumn{7}{c}{602} & & &
\end{tabular}




\begin{tabular}{lccccc} 
Regional Office & 5 & 0.7 & & - & - \\
Valid & 700 & 98.2 & 98.2 & 284 & 97.6 \\
Missing & 13 & 1.8 & & 7 & 2.4 \\
Total & 713 & 100.0 & & 291 & 100.0 \\
\hline
\end{tabular}

Source: Authors' Fieldwork

\subsection{Structural integrity of measuring instruments}

The inspection of the individual items on both questionnaires reveals high face validity; while the contents of the questionnaire were found to be relevant to the research question dealing with correctional officials' and offenders' views regarding the triggers of the DCS transformational change intervention, thereby suggesting high content validity. Regarding construct validity, it can be concluded, based on the results of face validity and content validity, that the two questionnaires utilised in the study measured what they were designed to measure in terms of the triggers of the DCS transformational change.

\subsection{Reliability analysis}

The suitability of data for factor analysis was assessed using the KMO measure of sampling adequacy and the Barlett's test for sphericity. The data sets in respect of correctional officials complied with the requirements of sampling adequacy and sphericity and could thus be subjected to factor analysis. For the offender variables, the data sets also complied with the requirements of sampling adequacy and sphericity. Lastly, it is significant to note that the Bartlett's test values for both correctional officials and offenders reached statistical significance $(p=0.000)$, thereby supporting the factorability of the correlation matrices. Therefore, based on the KMO measure of sampling adequacy and Barlett's sphericity test values, it is concluded that the data gathered were found suitable for factoring. Factor analysis was conducted through exploratory factor analysis techniques. The extraction method utilised was the Principal Component Analysis (PCA), and the rotation method used was the Direct Oblimin with Kaiser Normalisation.

\section{Data Analysis and Discussion of Findings}

\subsection{Descriptive statistics of the triggers of transformational change in the Department of Correctional Services}

Table 3 below presents percentages that represent correctional officials' and offenders' responses to questionnaire items which were meant to test correctional officials' and offenders' views regarding the triggers of transformational change in the Department of Correctional Services of South Africa. The table reveals that the majority of correctional officials and offenders both internal and external forces triggered transformational change within the South African Department of Correctional Services.

Table 3: Frequencies: Triggers of the DCS Transformational Change

\begin{tabular}{|c|c|c|c|c|}
\hline \multirow[t]{2}{*}{ Statement } & \multicolumn{2}{|c|}{ \%age For } & \multicolumn{2}{|c|}{ \%age Against } \\
\hline & Officials & Offenders & Officials & Offenders \\
\hline Financial reasons (e.g. expenses or losses, reduced budget) & 73.6 & $\mathrm{~N} / \mathrm{A}$ & 26.3 & $\mathrm{~N} / \mathrm{A}$ \\
\hline Political reasons (new political landscape in South Africa) & 78.4 & 70.1 & 21.5 & 29.8 \\
\hline Appointment of new top leadership (e.g. National Commissioner) & 79.9 & $\mathrm{~N} / \mathrm{A}$ & 20.1 & $\mathrm{~N} / \mathrm{A}$ \\
\hline Social objectives (the need to promote partnership with community) & 90.4 & 84.6 & 9.5 & 15.5 \\
\hline The need to respect human rights & 90.2 & 84.4 & 9.6 & 15.3 \\
\hline Ensuring optimal utilisation of human resources & 88.3 & $\mathrm{~N} / \mathrm{A}$ & 11.6 & $\mathrm{~N} / \mathrm{A}$ \\
\hline The need to enhance organisational effectiveness and efficiency & 89.9 & $\mathrm{~N} / \mathrm{A}$ & 10.0 & N/A \\
\hline Complaints about services from offenders & 81.9 & 74.3 & 18.1 & 25.4 \\
\hline Complaints from the community about increasing levels of crime & 84.5 & 76.9 & 16.0 & 23.2 \\
\hline Complaints from oversight bodies about human rights violations in prisons & 84.9 & 80.6 & 15.1 & 19.0 \\
\hline $\begin{array}{l}\text { Competitive forces (desire to conform to international standards and norms regarding treatment of } \\
\text { offenders }\end{array}$ & 83.6 & 80.5 & 16.3 & 19.4 \\
\hline Proactive thinking by executive leadership & 80.9 & $\mathrm{~N} / \mathrm{A}$ & 19.1 & $\mathrm{~N} / \mathrm{A}$ \\
\hline The need to reduce recidivism & 88.8 & 81.3 & 11.1 & 18.6 \\
\hline Other (e.g. good public image for DCS, parole grants, integration, and to address hardened offenders & 70.4 & 71.1 & 29.6 & 28.9 \\
\hline
\end{tabular}

Source: Authors' Fieldwork 
The column chart displayed below indicates the level of agreement with the statements on the triggers of the DCS transformational change on the part of both correctional officials and offenders in respect of their responses to the questionnaire items which relate to the triggers of the DCS transformational change. As can be seen from Figure 1, the distribution of frequency percentages in terms of correctional officials' and offenders' responses to the questionnaire items relating to the triggers of the DCS change shows that the majority of both correctional officials and offenders believed that the DCS transformational change was sparked off by factors located in both the internal and external environments of the Department of Correctional Services.

Figure 1: Frequency Distribution of DCS Transformational Change

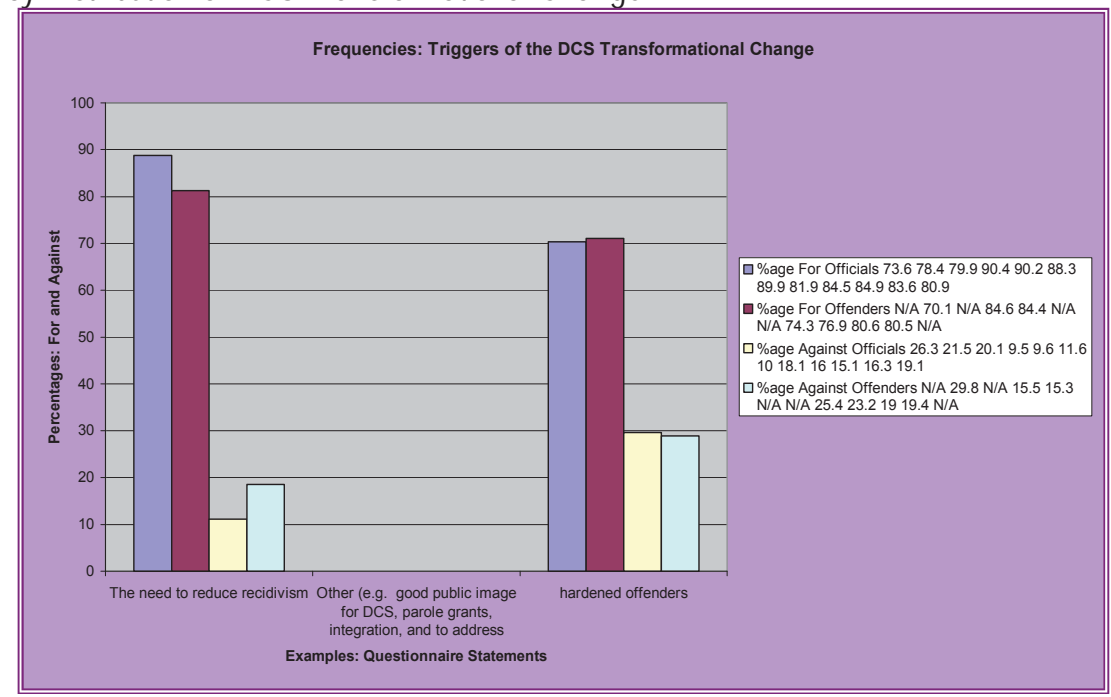

Source: Authors' Fieldwork

As indicated above in terms of both the table and the frequency distribution column chart, the triggers of transformational change in the South African Department of Correctional Services are divided into two categories, namely the internal driving forces and the external driving forces as discussed below. The identification of both internal and external forces as being behind the transformational change initiated and implemented in the Department of Correctional Services vindicates earlier empirical studies undertaken which identified forces of organizational change as coming from both the internal and external environments of the organisation. Duke (2011) emphasised that organisations were not static and as such, they need to change on a continuous basis as a response to a variety of forces emanating from both the internal and external environments. This assertion is in line with what was discovered earlier by Palmer, Dunford and Akin (2009), Kohurt (2010), and Turner (2011) that the need for constant change is brought about by the changing and increasing needs of customers, the globalisation of economy and work, the increasing competition due to globalisation, and the high rate of technological advancement (all external driving forces), as well as the need to control costs and increase efficiency (internal driving force), are all factors behind the desire for change on the part of organisations.

\subsection{Internal driving forces}

The internal forces identified by this empirical study as being behind the initiation and implementation of the transformational change from the punishment-oriented philosophy to the rehabilitation-driven approach in the South African Department of Correctional Services range from financial reasons, new top leadership, the need to optimise utilisation of human resources, the need to enhance organisational effectiveness and efficiency through to offenders' complaints about services rendered, proactive thinking by executive leadership, the need to reduce recidivism, the need to rehabilitate hardened offenders, as well as the need to promote good image of the Department of Correctional Services.

\subsection{Financial reasons}

The need to reduce costs and minimise losses as a result of reduced budgets allocated to the Department of Correctional 
Services are some of the financial reasons behind the paradigm shift from the punitive approach to the rehabilitative approach in terms of the treatment of sentenced offenders, which represents a fundamental culture change. The financial factors which have been identified as the drivers of the DCS transformational change are part of economic drivers of organisational change which fall within the internal and external environmental domains. The identification of financial reasons as a driving force for transformational change in the South African Department of Correctional Services is line with the assertion by Senior, 2002, ChildHope, 2004, Brimley and Garfield, 2009 and Lunenburg, 2010 that economic factors are the drivers of organisational change.

\subsection{Appointment of new top leadership}

The appointment of new top leadership in the department in the name of the National Commissioner and the Chief Deputy Commissioners sparked off the transformational change to rehabilitation. The visionary leadership demonstrated by these new executive managers set in motion the wheels of transformational change to rehabilitation. The finding that the new executive leadership in the Department of Correctional Services was the driving force behind the DCS transformational change supports an assertion by Gibson, Ivancevich, Donnelly and Konopaske (2012) that personnel changes at managerial level can be a source of organisational change. As Gibson et al (2012) put it, organisational relationships change due to changes in managerial personnel.

\subsection{Ensuring optimal utilisation of human resources}

The study also uncovered that the need to ensure the optimal utilization of human resources was also the driving force behind the initiation and implementation of the rehabilitation-focused transformational change in the Department of Correctional Services. This vindicates earlier findings by Bulach, Lunenburg, and Potter (2008) and Lunenburg and Ornstein (2008) that people issues issues or challenges are a source of organisational change.

\subsection{The need to enhance organisational effectiveness and efficiency}

The need to break the cycle of crime, as per the White Paper on Corrections (2005), was behind the introduction of the philosophy of rehabilitation as part of the DCS transformational change. What was perceived by the new top leadership as an increase in re-offending (popularly known as recidivism) motivated the new leadership to set in motion the process of organisational transformation within the Department of Correctional Services. The problem of re-offending is a serious challenge in South Africa and is rated at approximately 85\% - 94\% (Dissel \& Ellis, 2002; Department of Correctional Services, 2005). This high rate of re-offending poses a threat to South Africa' noble dream of creating a safe and secure society in the country, as envisioned in terms of Chapter 11, Section 198 of the Constitution. The perceived increase in re-offending pointed to weaknesses in the 'prison' system in terms of the measures used to correct offenders. The ineffectiveness of offender-correction measures utilised in terms of enhancing organisational performance pointed to the need for transforming the Department in order to enhance organisational performance in terms of effectiveness and efficiency. Therefore, the transformation to rehabilitation emanated from the need to address the issue of re-offending (Muntingh in Dissel \& Ellis, 2002), which threatens social stability, social cohesion, and social harmony that hold the key to the establishment and maintenance of a safe and secure society. The empirical finding that the need to enhance organisational effectiveness and efficiency was the driving force for transformational change in the South African Department of Correctional Services concurs with the earlier finding by Alexander and Alexander (2009) and Lunenburg (2010) that organisational performance gaps and the need to revamp organisational structures, systems, operations, processes, and procedures are some of the drivers of organisational change.

\subsection{Complaints about services from offenders}

The study also found that complaints from offenders about services rendered to them by the Department sparked off transformational change. Poor or lack of service delivery to offenders in line with human rights guaranteed to people in terms of Chapter 2 (the Bill of Rights) of the Constitution of the Republic of South Africa ignited the need for transformational change to rehabilitation within Correctional Services in South Africa in order to ensure that the delivery of services to offenders was undertaken within a culture of human rights. The finding that complaints about service delivery from offenders drove the need for transformational change within the South African Department of Correctional Services supports the assertion by Alexander and Alexander (2009) that poor or lack of service delivery is one of the drivers of 
organizational change.

\subsection{Proactive thinking by executive leadership}

It was one of the findings of the study on the triggers of transformational change in the Department of Correctional Services that proactive thinking by the executive leadership ushered in a process of transformational change. This is in line with the assertion by Lunenburg (2010) and Gibson, Ivancevich, Donnelly and Konopaske (2012) that progressive leadership is one of the sources of organisational change.

\subsection{The need to reduce recidivism}

Re-offending creates a perpetual cycle of crime in South Africa and the desire to break the cycle of crime through reducing re-offending also served as a driving force of transformational change in the Department of Correctional Services.

\subsection{Good public image for DCS, parole grants, integration, and to address hardened offenders}

It is a managerial responsibility to ensure effective organisational reputation management in order to ensure that a good public image of the organisation is maintained all the time. Therefore, the maintenance of good public image for the Department of Correctional Services was identified by the study as one of the drivers of the DCS transformational change. The need to deal effectively with hardened "criminals" (offenders) also served as a driving force of the DCS transformational change.

\subsection{External driving forces}

External forces identified through this empirical study as being the drivers of transformational change in the South African Department of Correctional Services include political factors, social factors, the need to respect human rights, complaints from the community about increasing levels of crime, complaints from oversight bodies about human rights violations in prisons, and competitive forces (desire to conform to international standards and norms regarding treatment of offenders.

\subsection{Political reasons}

The new political landscape in South Africa as a result of the democratic dispensation ushered in 1994 called upon and compelled organisational leadership to ensure the democratisation of their institutions. For example, the promulgation of the Labour Relations Act as a result of the need to democratise workplaces in line with the democratic dispensation meant that organisations needed to democratise in line with the dictates of the Labour Relations Act. Similarly, the adoption of the new Constitution of the Republic of South Africa meant that organisations needed to comply with the provisions of the Constitution as the supreme law of the country, particularly Chapter 2 dealing with the Bill of Rights. This requirement to comply with the Constitution prompted the Department of Correctional Services to usher in a process of transformational change with a view to extending human rights to offenders as well. Therefore, one can construe that political reasons were behind the initiation and implementation of transformational change in Correctional Services and as such, it can be generally concluded that political factors from the external environment are the drivers of organisational change, including transformational change as one of the three types of organisational change. This vindicates earlier findings by Bryson (1988), Senior (2002), ChildHope (2004) and Lunenburg (2010) that political factors do serve as sources of organisational change.

\subsection{Social objectives}

The realisation by the Department of Correctional Services leadership that social factors such as the breakdown of the family unit laid a fertile ground for offending behavior to manifest itself led to the acknowledgement and recognition that correcting offending behavior is not only a State responsibility but a societal one as well. The study found that due to the conviction that corrections was a societal responsibility, the Department of Correctional Services embarked on transformational change in order to propagate and promote the notion of corrections as a societal responsibility. In addition to the foregoing, the DCS leadership also acknowledged the fact that the establishment of partnerships with key 
stakeholders within the broader South African society and as such, the desire to enlist the support of community stakeholders in rehabilitating offenders became one of the driving forces behind the DCS transformational change in concurrence with the earlier findings that social reasons do serve as drivers of organizational change (Senior, 2002; ChildHope, 2004; Brimley \& Garfield, 2009; Lunenburg, 2010).

\subsection{The need to respect human rights}

One of the empirical findings relates to the fact that the need to respect offenders' human rights through not only establishing and maintain a human rights culture, but also extending human rights to offenders within a correctional environment in line with Chapter 2 (Bill of Rights) of the South African Constitution became one of the driving forces of the DCS transformational change. The need to respect human life and human dignity and to promote a human rights culture in correctional centres served as a source of the DCS transformational change. This was necessary in order to do away with the correctional environment that promoted a closed culture. This supports assertions by organisational change scholars and researchers that political factors (Bryson, 1988; Senior, 2002; ChildHope, 2004; \& Lunenburg, 2010) and social reasons (Senior, 2002; ChildHope, 2004; Brimley \& Garfield, 2009; Lunenburg, 2010) serve as drivers of organisational change.

\subsection{Complaints from the community about increasing levels of crime}

The study also found that complaints from the community about increasing levels of crime motivated the Department of Correctional Services to change its approach to treating offenders. This led to the adoption of the notion of rehabilitation as a new philosophy in terms of dealing with sentenced offenders, hence the initiation and implementation of transformational change, which represented a fundamental culture change, within the department. The finding that complaints from the community about the increasing levels of crime, a social issue, were the source of the DCS transformational change supports the argument by Senior (2002), ChildHope (2004), Brimley and Garfield (2009) and Lunenburg (2010) that social factors are some of the reasons that compel organisations to change.

\subsection{Complaints from oversight bodies about human rights violations in prisons}

The study established that complaints from domestic and international oversight bodies such as the Portfolio Committee on Correctional Services and the United Nations Commissions on Conditions in Prisons and Places of Detention about human rights violations in prisons were behind the implementation of a major transformational change initiative in the Department of Correctional Services. This empirical finding is line with the earlier assertions that political reasons do drive the need for organisations to undertake transformational changes (Bryson, 1988; Senior, 2002; ChildHope, 2004; Lunenburg, 2010).

\subsection{Competitive forces (desire to conform to international standards and norms regarding the treatment of offenders)}

Complaints from international bodies such as the United Nations regarding gross violation of human rights within the South African prison system, as well as the take-over of power by a democratic government in 1994, paved the way for the South African Correctional Services organisation to undergo a major transformational change initiative in order to conform to international standards and norms insofar as the treatment of offenders was concerned. This suggests that competition amongst countries regarding compliance with, and strict adherence to, international norms and standards regarding offender treatment compelled the Department of Correctional Services to undertake organisational transformation guided by the adopted vision to be one of the best in the world in providing a correctional service. The finding that the need to be competitive in terms of rendering correctional services on the part of the Department of Correctional Services of South Africa was one of the reasons behind the DCS transformational change vindicates the argument that the desire for competitiveness compels organizations to embark on organisational changes (Senior, 2002; ChildHope, 2004; Brimley \& Garfield, 2009; Lunenburg, 2010).

\section{Implication of Findings}

The implications of the findings is that all organisations aspire for competitive advantage and organizations can only achieve a competitive edge through undertaking and undergoing changes in their human and technical aspects. 
Therefore, for any organisation to prosper and gain sustainability and competitive edge in terms of its business performance, there should be a commitment to implementing transformational changes on an ongoing basis as a response to changes within the internal and external environments of the organisation. This suggests that organisations need to change on a continuous basis as a reaction to a various forces emanating from both the internal and external environments. In the light of the foregoing, transformational change denotes an organisation's response to the everchanging conditions within the internal and external organisational environment. Furthermore, one can argues that due to the constantly changing situations within the internal and external environments of the organisation, the organisation needs at all times to adapt to these changing conditions in order to remain relevant and effectual. Therefore, transformational change becomes a critical phenomenon to organisational growth and survival. Transformational changes are necessary in order to empower the organisation to meet the demands and challenges of the continuously changing internal and external and environments. Transformational change is not caused by a single factor, but by a multiplicity of factors which emanate from both the internal and external environments. It is important to also state that for every change that takes place within an organisation, there is a driving force, cause or source behind such a change which can be traced back to either the internal or external environment. The internal and external environmental factors are an impetus for transformational change.

Thus in the light of the above with regards to triggers of transformational change, it should be noted that personnel changes at managerial level can be a source of transformational change. Hence the ability of organisational leaders to diagnose the need for strategic change lies at the centre of the successful implementation of transformational change interventions. More than that, the desire to enhance the optimal utilisation of human resources is also one of the drivers of transformational change. Also, the need to enhance organisational performance in terms of effectiveness and efficiency does serve as a source of transformational change. The foregoing suggests that poor or lack of service delivery is also a driving force behind the implementation of transformational change intervention. In addition, the desire to ensure effective organisational reputation management in order to ensure that a good public image of the organisation is maintained is a cause for transformational change. Additionally, political, social and financial considerations do serve as compelling reasons for organisations to undertake transformational changes. Anticipating, responding, adjusting and adapting to the changing environmental conditions is a necessity if organisations are to remain relevant, efficacious and competitive. In the light of the ever-changing organisational environmental conditions, the challenge is for organisational leaders to recognise and respond to all the internal and external factors that affect their organisations. The second challenge is for organisational leaders to anticipate and direct change processes so that organisational performance in terms of effectiveness and efficiency is improved. Therefore, for managers to be able to deal effectively with changes emanating from within their organisational environments, they must learn to determine the nature of change occurring. It is critical for managers to manage both environments through regular scanning so as to be able to anticipate and manage organisational environmental changes effectively. Progressive and dynamic organisational leadership, like in the one found in the Department of Correctional Services, plays a significant role in the initiation, implementation, institutionalisation, and sustenance of transformational changes as a response to changes in the broader organisational environment.

\section{Conclusion}

The results of the empirical study have revealed that both internal and external organisational environmental factors are the source of transformational changes that take place in organisations. The factors that served as the drivers of the transformational change from the punishment-oriented paradigm to the rehabilitation-driven paradigm in the South African Department of Correctional Services emanated from both the internal and external environments of the Department as an organisation. In their efforts to enhance the performance of their organisations in terms of effectiveness and efficiency, organisational leaders must anticipate, respond to, and direct changes that occur within the broader organisational environment (both the internal and external environments of the organisation). If organisations ignore changes (be they political, economic, social, technological or operational inside the organisation) that take place within organisations, they do so at their own peril. Ignoring changes in the internal and external environments of the organisation will have a negative impact in terms of organisational functioning, organisational performance in terms of effectiveness and efficiency, organisational health and organisational sustainability, thereby leading to organisational decline, organisational failure, and ultimately organisational collapse or decay. Therefore, managing internal and external environmental factors that have an influence of the functioning of an organisation becomes one of the overarching managerial responsibilities of organisational leadership. It is on the basis of the foregoing that progressive and dynamic leadership becomes one of the critical traits of organisational leadership. 


\section{References}

Agboola, A.A. \& Salawu, R.O. (2011). Managing deviant behaviour and resistance to change. International Journal of Business and Management. 6(1), 235-242. American Productivity \& Quality Center (1997). "Organizational Change: Managing the Human Side." Retrieved April 4, 2007, from http://www.exinfm.com/pdffiles/change_apqc.pdf

Alexander, K, \& Alexander, M. D. (2009). American public school law (7th ed.). Belmont, CA: Wadsworth/Cengage Learning.

Blankstein, A. M. (2010). Failure is not an option: 6 principles for making student success the only option (2nd ed.). Thousand Oaks, CA: Sage.

Bourne, M. \& Bourne, P. (2002). Change management in a week. London: Hodder \& Stoughton.

Bridle, P. (2010). So you want change. Management Today. 28(3), 56.

Brimley, V. \& Garfield, R. R. (2009). Financing education in a climate of change (10th ed.). Boston, MA: Allyn \& Bacon.

Bryson, J. M. (1988). Strategic planning for public and nonprofit organizations: A guide to strengthening and sustaining organizational achievement. San Francisco: Jossey-Bass.

Burnes, B. (2004). Managing change: A strategic approach to organisational dynamics. $4^{\text {th }}$ ed. Harlow: Prentice Hall.

Canadian Society for Chemical Engineering. (2004). Managing the health and safety impacts of organizational change. Retrieved from http://www.chemeng.ca on 24 September 2011.

ChildHope (2004). "Organizational Assessment for Development Planning." Retrieved April 4, 2007, from http://www.childhope.org.uk/resources/oadp-part3.pdf

Cook, S., Macaulay, S., \& Coldicott, H. (2005). Change management excellence. Using the four intelligences for successful organizational change. Retrieved from: http://www.google.com on 04 May 2012.

Corbeau, J. \& Sijats, J. (2005). Case Study: Implementation of a change process within Smaland Airport. Vaxjo University

Creemers, B. (2011). Improving quality in education: Dynamic approaches to school improvement. New York, NY: Routledge.

D'Augustino, S. (2011). Adaptation, resistance, and access to instructional technologies: Assessing future trends in education. Hersey, PA: IGI Global.

Department of Correctional Services. (2005). White Paper on Corrections in South Africa. Pretoria: Government Printers.

Dissel, A. \& Ellis, S. (2002). Reform and Stasis: Transformation in South African Prisons. Ambitions réformatrices et inertie du social dans les prisons sudafricaines", "http://www.ceri-sciences-po.org/" Critique Internationale, No. 16.

Duke, D. L. (2011). The challenges of school district leadership. New York, NY: Routledge.

Flash, G. (2007). Organization change and its impact. Managing organization change. Satisfying motivational needs and achieve meaningful work. Retrieved from: http://www.diypc.wordpress.com on 09 February 2011.

Fullan, M. (2009). The challenge of change. Thousand Oaks, CA: Sage.

Fullan, M. (2010). All systems go: The change imperative for whole system reform. Thousand Oaks, CA: Corwin Press.

Gibson, J. L., Ivancevich, J. M., Donnelly, J. H., \& Konopaske (2012). Organizations: Behavior, structure, processes (14th ed.). New York, NY: McGraw-Hill. Herold, D.M. \& Fedor, D.B. (2008). Change the way you lead change: Leadership strategies that really work. Stanford, CA: Stanford University Press.

Imberman, M.D. (2009). Organizational change and organizational justice: Assessing the impact on organizational commitment, change-oriented organizational citizenship behaviour, and attitude toward future change. PhD Dissertation. ProQuest Dissertations and Theses, 2011/09/08, Alliant International University, Los Angeles, California.

Johnson, R. (2012). Change is a fact of life... Six keys that make a difference. Retrieved from: http://www.google.com on 09 May 2012.

Jones, G. R. (2004). Organization Theory, Design, and Change. New York: Addison-Wesley Publishing Company.

Kerlinger, F. (1992). Foundations of behavioural research. Florida: Harcourt Brace College Publishers.

Kline, R. B. (2004). Principles and practice of structural equation modeling. $2^{\text {nd }}$ ed. New York: Guildford.

Kohurt, A.M. (2010). Significant workplace change: Perspectives of survivors. D.Ed Dissertation. Northern Illinois University, Dekalb, Illinois.

Lefkoe, M. (2010). What is the relationship between personal and organizational transformation? Retrieved from: http://www.google.com on 23 July 2009.

Lew, C. \& Eekhout, N. (2004). Managing change from the inside out. Management Today, March, 20(2), 30-31.

Lines, R. (2005). The structure and function of attitudes towards organizational change. Human Resource Development Review, 4(1), 8-32.

Liu, Y. (2010). When change leadership impacts commitment to change and when it does n't. A multi-dimensional investigation. PhD Dissertation. Georgia Institute of Technology.

Lunenburg, FC. (2010). Forces for and resistance to organizational change. National Forum of Educational Administration and Supervision Journal, 27 (4),

Maltz, M. (2008). Managing resistance to change. TRIAD Consulting Group LLC. Retrieved from: http://www.google.com on 10 October 2011.

Martins, L. (2008). Organisational development and change. Manuscript prepared for S. Zedeck (ed). APA Handbook of Industrial and Organizational Psychology, Vol III.

Muntingh, L. (2007). Prisons in South Africa's Constitutional Democracy. Centre for the Study of Violence and Reconciliation. Criminal Justice Programme

Nelissen, N.J.M \& Scheepers, P.L.H. (1992). Ecological consciousness and behaviour examined: An empirical study in the Netherlands. Social Wetenschappen, 35 (4), 64-81.

Osborne, S.P. \& Brown, K. (2005). Managing change and innovation in public service organizations. New York: Routledge.

Palmer, I, Dunford, R \& Akin, G. (2009). Managing organizational change: A multiple perspectives approach. $2^{\text {nd }}$ ed. New York: McGraw-Hill/Irwin.

Palmer, I, Dunford, R \& Akin, G. (2009). Managing organizational change: A multiple perspectives approach. $2^{\text {nd }}$ ed. New York: McGraw-Hill//rwin.

Pearlstein, S. (1993). Layoffs become a lasting reality.Washington Post, pp. A1, A10.

Perlmutter, F.D., \& Gummer, B. (1994). Managing organizational transformations. In R.D. Herman \& Associates (Eds.), The Jossey-Bass handbook of nonprofit leadership and management (pp. 227-246). San Francisco: Jossey-Bass.

Perlmutter, F.D. (2000). Initiating and implementing change. In R. J. Patti (Ed.), The handbook of social welfare management (pp. 445-457). Thousand Oaks, CA: Sage Publications.

Robinson, R. (2010). Employment regulations in the workplace: Basic compliance for managers. New York, NY: M. E. Sharpe.

Senior, B. (2002). Organisational Change. (2nd Ed). Financial Times/Prentice Hall Books

Smylie, M. A. (2010). Continuous school improvement. Thousand Oaks, CA: Corwin Press.

Spector, B. (2011). Implementing organizational change: Theory into practice - international edition. Upper Saddle River, NJ: Prentice Hall.

Szarlan, J. (2011). Striving for excellence: A Manual for goal achievement. Upper Saddle River, NJ: Pearson Education.

Turner, D. (2011). The paradox of change management. Turner Change Management Inc. Dated 30 July 2011. Retrieved from: http://www.google.com on 16 July 2011

Van de Ven, A.H. \& Poole, M.S. (1995). Explaining development and change in organizations. Academy of Management Review, 20 (3), $510-540$.

Wharton Executive Education. (2011). Harnessing fire: Managing emotions for successful organizational change. Wharton@work. E-Newsletter for the Aresty Institute of Executive Education. 